\title{
Team Teaching and Situational Leadership Theory: Adapting and Combining Frameworks for Japanese English Education
}

\author{
Eric Hawkinson \\ The University of Fukuchiyama, Fukuchiyama, Japan
}

\begin{abstract}
With the goal of better understanding a healthy working relationship between two teachers co-teaching in the same classroom on the same subject, this study takes a look at leadership related behaviors in team teaching environments. The study looks at relationships between teams of teachers in Miyazu City School District, a rural Japanese school district teaching English language in public K-12 schools. The relationships of team teachers are analyzed from the perspective of leadership and leadership theory. Situational leadership is presented as a means to understand the social dynamic at play when two teachers are conducting a class and how these ideas can be suited directly to behaviours of team teachers both in and out of class. The result is the creation of a new framework based on existing team teaching and situational leadership models to better understand and improve on working relationships of team teachers.
\end{abstract}

Keywords: team teaching, situational leadership, educational leadership theory, co-teaching, language education

\section{Team Teaching Background}

Team teaching is closely related to the more common term co-teaching. Co-teaching is described as two or more teachers who are equal in status working together and providing instruction in the classroom (Dieker \& Murawski, 2003). That definition does not quite fit team teaching for the purposes of this study as the teachers working together are not equal in status. This shifts the definition closer to that of leadership, as most definitions of leadership involve a leader and a follower (Northouse, 2012). It is this inequality that makes examining team teaching through the lens of leadership theory an attractive idea.

\section{Team Teaching in Language Learning}

Although co-teaching has been implemented in many classrooms for many subjects and levels, it has been widely utilized in special education (Friend et al., 2010), mainly due to the individual attention students need in those classrooms. In Japan and other Asian countries, team teaching is widely used in language learning Japan and the Ministry of Education, Culture, Sports, Science and Technology (Japan MEXT, 2014). Team teaching in this context happens when a certified Japanese teacher of English is paired with a native English speaker to teach English classes in tandem at public and private schools. The idea is to have the students benefit from teaching experience as well as gain practical experience using the language.

Eric Hawkinson, associate professor, Department of Rural Revitalization, The University of Fukuchiyama. 


\section{Team Teaching in Japan and the Miyazu Board of Education}

Japan is falling behind other Asian countries in English learning (Aoki, 2005). Japan currently ranks near the bottom among its Asian neighbors despite a rigorous English education curriculum that now starts in elementary school. One of the possible reasons for the lack of English fluency is the lack of opportunity for Japanese students to interact with native speakers of English. As a result, the Japanese Ministry of Education, Culture, Science, and Technology has implemented programs to bring teachers and students from English speaking countries to Japan. One popular idea employed in schools for English education is team teaching. The Miyazu City Board of Education manages all elementary and junior high public schools as well as social welfare and public education programs. The district of schools consists of two pre-schools: seven elementary schools and three junior high schools. Miyazu is located next to the Sea of Japan in the Northern Kyoto prefecture. Studying a foreign language is a graduation requirement for the students. Each school has at least one Japanese person who teaches English, also called a Japanese teacher of English (JTE). The Miyazu City Board of Education is responsible for two native speakers of English who act as assistant language teachers (ALT) to the JTE. This makes for an interesting situation as far as leadership, because one ALT will team up with several JTEs during the work week and the leadership dynamic can change dramatically. Not only can the team teaching style change, but a whole different set of leadership traits and styles. Notably, there is no formal training provided by the Miyazu Board of Education (BOE) to help ALTs and JTEs better understand their roles. This forces both members to adjust leadership assertiveness constantly and feel out the particulars of their roles as the relationship develops.

\section{Team Teaching Approaches to Leadership}

Team teaching styles in this context can be broken into categories by simply identifying the roles of ALT and JTE. Which team member is leading and which is following drives the style of content delivery and sometimes even pedagogical goals (Council of Local Authorities for International Relations (CLAIR), 2013).

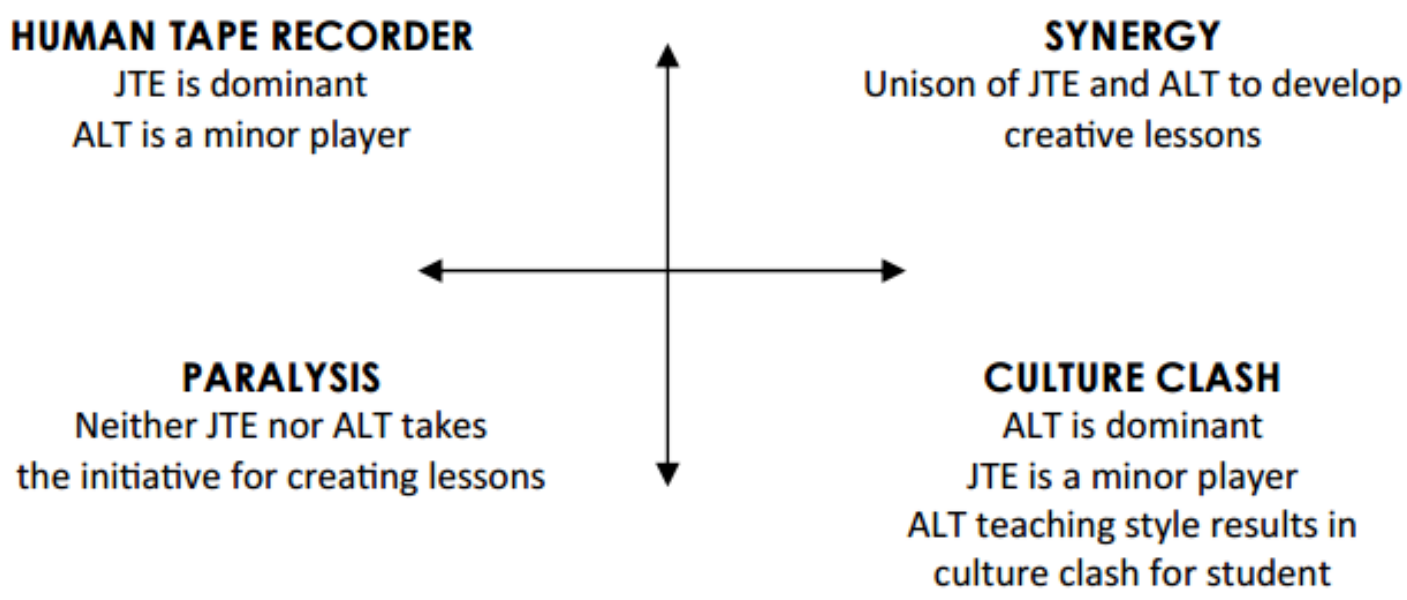

Figure 1. Four team taching environments (Source: CLAIR, 2013).

In this representation of team teaching, the dominant member is identified to infer what style of team teaching is taking place. Each axis represents a team teacher and the higher of their respective axis the more 
involved that team member is in leading and planning lessons. It is hinted in this model that a high level of involvement by both team members raises the quality of lessons by synergizing the talents of each member. Transversely when neither member takes initiative and a state of paralysis hinders the creation of quality lessons (CLAIR, 2013).

This representation helps explain how the team dynamic with respect to initiative and dominance relates to team taught lessons, but initiative and dominance are not the only important traits to leadership. For a framework to become better useful to team teachers, it can better incorporate theories of leadership with observed team teaching dynamics like the ones expressed in Figure 1.

Northouse (2012) explained that traits of leaders largely relate to social intelligence. Characteristics, like confidence, openness, and emotional stability define how a leader leads and if they become leaders at all. In the case of team teaching, extraversion and agreeableness are traits that will be important in defining how pronounced roles in the classroom are. In studies of traits and characteristics of leadership, initiative and dominance have been discussed. Stogdill (1974) found that the drive to exercise initiative in social situations was one of 10 identified traits positively associated with leadership. Lord, DeVader, and Alliger (1986) found in a meta-analysis on leadership that intelligence, masculinity, and dominance were important traits to how we perceive leaders. Another model which was created that also looks at team teaching relationships and how they inform how lessons are conducted. This approach considers the share of time controlled by each team member rather than initiative or dominance.

Table 1

Team Teaching Matrix

\begin{tabular}{|l|l|l|}
\hline \multirow{5}{*}{$\begin{array}{l}\text { Non-jointly } \\
\text { directed }\end{array}$} & $\begin{array}{l}\text { Chalk and talk } \\
\text { "The human tape recorder" } \\
\text { Directed by the JTE, this style consists of a lecture } \\
\text { (mostly in Japanese) of English grammar. Often, the } \\
\text { JTE and AET will demonstrate a model dialog. In this } \\
\text { style the AET's main contribution is to read a passage } \\
\text { or set of vocabulary to have the students hear and } \\
\text { repeat. } \\
\text { Advantage: } \\
\text { Effective in preparing for standardized English exams. } \\
\text { "Hispy Fun Time" } \\
\text { This is when the AET is given complete freedom to } \\
\text { design a lesson. It often includes "fun" activities that } \\
\text { focus on practical communication. } \\
\text { Advantage: } \\
\text { Inspires active participation from the students. } \\
\text { Disadvantage: } \\
\text { Often off-topic or unrelated to what will be tested on. } \\
\text { usage of English. }\end{array}$ \\
\hline $\begin{array}{l}\text { Time assigned/shared } \\
\text { "Tag-Team Teaching" } \\
\text { A common approach to team teaching that includes a } \\
\text { chalk and talk lecture followed by a communicative } \\
\text { activity that employs what was just taught. } \\
\text { Advantage: } \\
\text { Students are able to practice real world usage of an } \\
\text { understood grammar. } \\
\text { Disadvantage: } \\
\text { Time is often clearly divided between the JTE and } \\
\text { AET and can be limitedly involved when the other's } \\
\text { portion of class. }\end{array}$ & $\begin{array}{l}\text { Jointly directed } \\
\text { "True Team Teaching" } \\
\text { A form of team teaching were the true leader of the } \\
\text { lesson is relatively unapparent. Grammar is introduced, } \\
\text { demonstrated, and discussed at the time by both the } \\
\text { AET and JTE. Of all the styles Japanese is used the } \\
\text { least. } \\
\text { Advantage: } \\
\text { Balanced approach. } \\
\text { Disadvantage: } \\
\text { Requires the most preparation. }\end{array}$ \\
\hline
\end{tabular}

Note. Hawkinson \& Ogasawara, 2008. 
This matrix can illustrate the differences in teaching goals and styles with both leader follower roles and between team and co-teaching where leadership is more ambiguous (see Table 1). It can also be used to explain how various leadership theory can be applied to team teaching. The matrix also points out advantages and disadvantages to each team teaching environment, suggesting that learning goals should also be considered when discussing team teaching styles. This approach to looking at team teaching puts more emphasis on the skills of team members and less on their personality traits. When considering a three-skills approach developed by Mumford et al. (2000) and putting team teachers in a lower management category, both technical and human skills are important for leadership (Katz, 1974). The technical skills in team teaching are related to language ability and teaching experience and human skills are related to intercultural communication. The level of these skills vary greatly between ALTs and JETs.

\section{Other Leadership Theories and Team Teaching}

Contingency theory relates leader-member relations, task structure, and position power to find a person's least preferred co-worker (LPC) scale (Fielder, 1967). The scale indicates if a leader is more task or relationship motivated. Team teachers will work better together when their LPCs are aligned, which in-turn is in part related to how well the classes are structured, which is largely more structured in junior high school. It might be beneficial when teaming teachers together to try to team a task motivated teacher with a relationship one for a balanced classroom.

Team leadership theory introduces ideas that help make choices for better group effectiveness. It involves examining internal (self) or external (group) issues and appropriate intervention. Every member of a group does this to some degree (Fleishman et al., 1992). All members of a team monitor internal and external issues and take actions. In the case of Miyazu, most internal issues of the team teaching partnership are shared but may be perceived differently, perhaps based on cultural backgrounds or preferred pedagogical approach to language teaching. External factors many times weigh on the JTE as they are ultimately responsible for students in their classrooms and answer not only to administration as ALTs do, but also parents and entrance testing criteria for students. Hill's model for team leadership describes some internal tasks that both teachers with internal or external responsibilities can employ, such as goal focusing and maintaining standards (Northouse, 2012).

Cultural issues in leadership are also key in analyzing team teaching in team teaching in Japan (Tajino \& Tajino, 2000). Hofstede's (1983) cultural dimensions can help team teachers from different countries to better understand each other's backgrounds and priorities. As in many cases, teams of teachers are working together without prior contact, these cultural dimensions can be a starting point to build leadership strategies for more productive lessons.

\section{Analysis of Leadership in Team Teaching in Japan}

There is no formal training provided by the Miyazu BOE for team teaching. In most situations, ALTs and JTEs are meeting for the first time minutes before their first lesson together in the classroom. This makes teachers take and give responsibility without much prior warning. Experienced team teachers both ALT and JTE find a balance that works for them based on how well they can perform the various roles on the team teaching matrix. Educational policy in the district also has a part in pushing team teachers into certain roles and team teaching styles. For example, there is no established English curriculum in elementary schools, but in junior high schools, the entrance exam system has teachers highly restricted in instructional pace and content. 
In general, this means higher tendency toward ALT directed lessons in elementary schools and more chalk and talk in junior high.

\section{Situational Leadership Theory and Team Teaching}

Situational approach to leadership uses levels of supportive and directive behavior (Blancard, Zigarmi, \& Zigarmi, 1985). Of all the leadership theories discussed, thus, far situational leadership is the most relatable to team teaching. One reason is that it is easy to conceptualize and can be applied in all leadership levels (Northouse, 2012). In the case of team teachers, the behaviors can be reciprocal. When thinking about team teaching on the matrix in Figure 2, when one teacher is delegating (low support and low directive), the other teacher is invited to lead the lesson, and therefore, becomes more team teaching than co-teaching. Using diagrams on the four leadership styles in situational leadership created by Blanchard et al. (1985), ideas of team teaching were incorporated to create a framework.

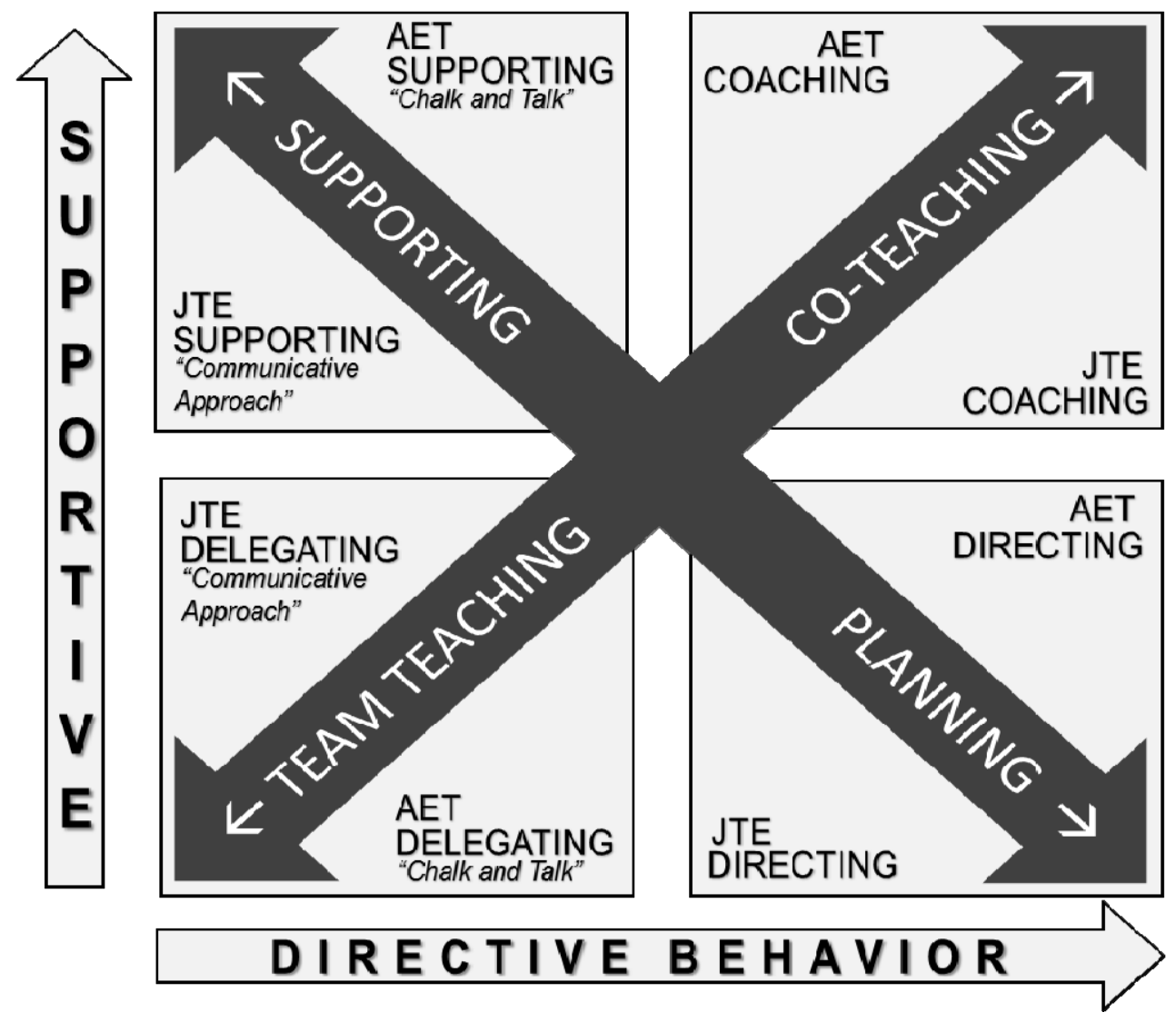

Figure 2. Situational team teaching matrix.

Using the four styles of situational leadership, we can better understand the roles teachers are playing in the classroom. The four styles include delegating, supporting, coaching, and directing and are found on a chart by measuring the level of supportive and directive behaviour a leader demonstrates. The combination of support and delegating suggesting a more balanced and equal approach, and thus, better fits a co-teaching definition, the less of both is leaving the lion's share of responsibility on the partner and is more likely to be only of the team teaching styles on the team teaching matrix. 


\section{Using the Situational Team Teaching Matrix}

Prior frameworks helps team teachers to identify what kind of team teaching environment they were engaging in, and then could analyze weather that style was suitable for the learning goals. The situational team teaching matrix allows each team member to individually measure how they are contributing to the team and then see if each team member is taking on a role that on complementary to the team. Team teaching environments are best when each member build on each other's experience and strength, allowing students to benefit from the knowledge and experience of each team member (Tajino \& Tajino, 2000). So, team members should be trying to change positions on the matrix as much as possible. Therefore, it might be helpful for each team member to place themselves by their behaviours and then look to find a change in behavior that would switch from more supportive to directive or vice versa. If team teachers are more aware of the traits, skills, and type of support they bring to the classroom, it becomes possible to target desirable behaviors and work on eliminating unproductive ones.

\section{Further Research}

Some next steps in research mostly revolve around possible practical applications in team teaching and co-teaching research. The framework can be used to help in investigating a wide range of issues related to team and co-teaching, such as leadership strategies, effective team building and teamwork behaviors, and connections of team teaching roles to effective learning.

\section{References}

Aoki, K. (2005). Japanese higher education institutions in the 21st century: The challenge of globalization and internationalization. Electronic Journal of Contemporary Japanese Studies.

Blake, R. R., \& McCanse, A. A. (1991). Leadership dilemmas: Grid solutions. Houston, T.X.: Gulf.

Blanchard, K. H., Zigarmi, P., \& Zigarmi, D. (1985). Leadership and the one minute manager. New York, N.Y.: William Morrow and Company.

Bouck, E. C. (2007). Co-teaching ... not just a textbook term: Implications for practice. Preventing School Failure: Alternative Education for Children and Youth, 51(2), 46-51.

Council of Local Authorities for International Relations (CLAIR). (2013). Assistant language teacher handbook. Japan Exchange and Teaching (JET) Programme.

Dieker, L. A., \& Murawski, W. M. (2003). Co-teaching at the secondary level: Unique issues, current trends, and suggestions for success. The High School Journal, 86(4), 1-13.

Fiedler, F. E. (1967). A theory of leadership effectiveness. New York: McGraw-Hill.

Fleishman, E. A., Mumford, M. D., Zaccaro, S. J., Levin, K. Y., Korotkin, A. L., \& Hein, M. B. (1992). Taxonomic efforts in the description of leader behavior: A synthesis and functional interpretation. The Leadership Quarterly, 2(4), 245-287.

Friend, M., Cook, L., Hurley-Chamberlain, D., \& Shamberger, C. (2010). Co-teaching: An illustration of the complexity of collaboration in special education. Journal of Educational and Psychological Consultation, 20(1), 9-27.

Hawkinson, E., \& Ogasawara, S. (2008). Effective team teaching. In Proceedings of 2008 Kyoto Prefectural English Education Conference, Kyoto, Japan.

Hofstede, G. (1983). National cultures in four dimensions: A research-based theory of cultural differences among nations. International Studies of Management \& Organization, 13(1/2), 46-74.

Japan, Ministry of Education, Culture, Sports, Science and Technology (MEXT). The British Council. (n.d.). ALT Handbook.

Katz, R. L. (1974). Skills of an effective administrator. Harvard Business Press.

Lord, R. G., DeVader, C. L., \& Alliger, G. M. (1986). A meta-analysis of the relations between personality traits and leadership perceptions: An application of validity generalization procedures. Journal of Applied Psychology, 71, 402-410.

Ministry of Education, Culture, Sports, Science and Technology. (1994). Handbook for team-Teaching. Tokyo: Gyosei. 
Mumford, M. D., Zaccaro, S. J., Harding, F. D., Jacobs, T. O., \& Fleishman, E. A. (2000). Leadership skills for a changing world: Solving complex social problems. The Leadership Quarterly, 11(1), 11-35.

Northouse, P. G. (2012). Leadership: Theory and practice (6th ed.). Los Angeles, C.A.: SAGE Publications, Inc..

Scruggs, T. E., Mastropieri, M. A., \& McDuffie, K. A. (2007). Co-teaching in inclusive classrooms: A metasynthesis of qualitative research. Exceptional Children, 73(4), 392-416.

Stogdill, R. M., (1974). Handbook of leadership: A survey of theory and research. New York: Free Press.

Tajino, A., \& Tajino, Y. (2000). Native and non-native: What can they offer? Lessons from team-teaching in Japan. ELT Journal, 54(1), 3-11. 